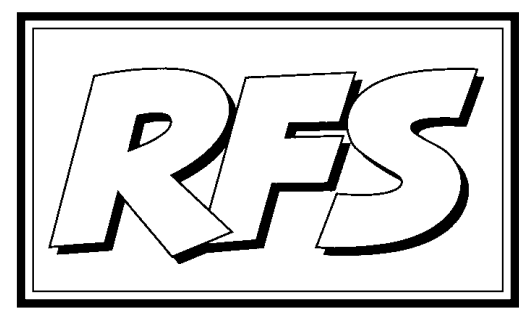

Revista de Fomento Social, 57 (2002), 357-367

\title{
El movimiento de los sin tierra en Brasil
}

\section{Carlos FRITZEN}

\section{Introducción}

Brasil, el coloso de Sudamérica por su dimensión territorial (8.511.965 $\mathrm{Km}^{2}$ ) y por su número de habitantes, 169 millones, ocupa el quinto lugar en la escala mundial y, por su economía, se le asigna el casillero número nueve, aunque tiene la triste suerte de ser el primero mundial en concentración de la renta. Según datos del Instituto Brasileño de Geografía y Estadística, los ingresos del 1\% más rico de la población representan el 13,9\% del total, el $49 \%$ rico restante se apropia del $74,1 \%$ de los ingresos, mientras que al $50 \%$ más pobre correspondeel $12,0 \%$ de los ingresos. El 1\% más rico se apropia de más ingresos que el $50 \%$ más pobre. Así, mientras, por un lado, los indicadores hablan de Brasil como una potencia económica (en 1998 tenía un PIB de 778 mil millones de dólares USA ${ }^{2}$ ); por otro lado, los cálculos oficiales reconocen que 32 millones de brasileños sobreviven en la pobreza absoluta.

1 Jesuita. Asesor del MST, Centro Santa Fé. Saô Paulo, Brasil.

2 V. Donoso (Dir.) (2000), Claves de la economía Mundial. Ed. ICEX, Madrid, p. 627. 
Haciéndose eco de esta realidad, el presidente Fernando Henrique Cardoso señaló, durante su campaña electoral, que Brasil no es un país subdesarrollado, sino "un país injusto"; sin embargo, después de asumir el poder a inicios de 1995, desairando a sus electores, que esperaban la adopción de medidas de justicia social, colocó en el centro de su gestión la modernización neoliberal, precisando que estaba firmemente decidido a adoptar los dictámenes del Fondo Monetario Internacional y del Banco Mundial para ajustar la economía a las normas de la globalización.

Bajo esta perspectiva, Cardoso no dudó en utilizar todos los recursos del poder para desactivar las protestas sociales que se le fueran presentando en el camino, como fue la huelga de los trabajadores petroleros en defensa del patrimonio nacional, "rota" sin contemplación alguna. Cuando parecía que el escenario era todo suyo, el país se vio sacudido por el viejo problema de la distribución de la tierra. En este fenómeno destacaron las movilizaciones protagonizadas por los trabajadores rurales sin tierra, sobre todo por la ocupación de propiedades improductivas y la gran solidaridad ciudadana que generaron.

El impacto fue tal, que el Gobierno se vio forzado a incluir el tema de la reforma agraria en la agenda política y a reconocer al Movimiento de los sin tierra (MST) como un actor clave en la lucha por esta causa. Esta conquista, con toda la importancia que tuvo, resultará parcial hasta que no se traduzca en resultados concretos, para lo que es necesaria la solidaridad internacional, que logre que el Gobierno brasileño entienda que la justa causa de los sin tierra es una causa de todos los sectores democráticos del mundo.

\section{El problema de la concentración y de la utilización de la tierra en Brasil}

En Brasil la distribución de la tierra es una de las más dramáticamente desiguales del mundo, por los contrastes que registra: cerca del $1 \%$ de los propietarios posee cerca del $46 \%$ de todas la tierras, mientras que al $90 \%$ de los propietarios le corresponde algo menos del $20 \%$ de la propiedad. Todo esto con el agravante de que tan sólo se cultiva un poco más del $50 \%$ de las tierras cultivables y de que en el país existen cerca de cinco millones de familias de trabajadores rurales sin tierra. La concentración de la tierra trae aparejada la concentración de la propiedad de los medios de producción económica, de la renta y del poder político en el medio rural, lo que repercute en una sociedad permanentemente conflictiva. Entre la minoría de propieta- 
rios y un gran sector de la población que, si no está explotado, se ve excluido de las fuentes de trabajo y de desarrollo, la conflictividad estructural es constante. Los graves problemas agrarios que existen son resultado del tipo de desarrollo que se ha realizado en el país, particularmente en las regiones rurales y en el sector agrario. La gravedad de tales problemas tan sólo es aceptada como tal por los trabajadores y la mayoría de la población, más no por la elite dominante, beneficiaria directa de ese esquema de desarrollo que tiene como resultado para ella una mayor oportunidad de lucro y poder.

De las alrededor de 400 millones de hectáreas con título de propiedad privada, apenas 60 millones son utilizadas para la labranza. La inmensa mayoría de las tierras están baldías, son mal aprovechadas, subutilizadas, se destinan a la ganadería extensiva o, simplemente, a la especulación o sirven como reserva de valor. Según datos del Instituto Nacional de Colonización y Reforma Agraria (INCRA), existen en Brasil cerca de 100 millones de hectáreas de tierra ociosas, localizadas en las grandes propiedades y que podrían ser aprovechadas (y de acuerdo a la ley actual, expropiadas). Estos son datos reconocidos por un organismo oficial, lejanos de sospecha de sobredimensionar el problema. La utilización de la tierra responde únicamente a la lógica de maximización del lucro. En muchas regiones próximas a las grandes ciudades, las tierras tan sólo han servido como área para los pasatiempos de las clases dominantes.

Esta distribución y explotación de la tierra han provocado el éxodo rural y migración hacia las ciudades. La migración de las poblaciones rurales hacia los conglomerados urbanos es un proceso natural y constante en todas las sociedades y a lo largo de la historia de muchas civilizaciones. No obstante, en el caso brasileño, resultan espantosos y llamativos tanto la velocidad como el volumen de personas que tuvieron que emigrar de sus comunidades rurales de origen, al ser expulsados del campo y verse obligados a buscar en las ciudades su única posibilidad de supervivencia. Según estadísticas oficiales, en el período de 1970-90, cerca de 30 millones de personas migraron hacia las ciudades, sobre todo a las grandes, dando origen a la formación de nuevas metrópolis. Y esto está generando enormes problemas sociales y económicos para las personas que emigran y para las ciudades que las reciben. Hubo también una intensa migración interna por la que miles de familias se desplazaron de una región a otra en busca de trabajo, tras el sueño de tener tierra para trabajar. Asimismo, más de 500.000 personas emigraron a Paraguay, Bolivia y Argentina en busca de trabajo en el campo, de las que la mayoría desea hoy regresar a Brasil. Otros problemas se unen a éste más 
central de los desplazamientos humanos: las condiciones precarias de trabajo en el campo, la situación de la mujer en el trabajo, el trabajo infantil, el modelo tecnológico de desarrollo de la agricultura, etc..

\section{Historia del Movimiento de los Sin Tierra}

El Movimiento de los Trabajadores Rurales sin Tierra (MST) es la organización que articula a los campesinos que luchan por la tierra y por la reforma agraria en Brasil ${ }^{3}$. EI MST es un movimiento de masas autónomo, al interior del movimiento sindical, sin vinculaciones político-partidarias o religiosas.

EI MST adquiere su relevancia en el contexto brasileño debido a su organización original y por su actuación critica hacia el Gobierno que se resiste a la reforma agraria. La forma de organización y de lucha, así como la concepción de política rural del MST son algunos de los indicadores que sirven para mostrar y hacer comprender los logros alcanzados por el Movimiento.

La historia del MST sirve para mostrar su actual identidad. De alguna manera el MST surge en continuidad con las luchas campesinas de siglos pasados, pero también implica una nueva fase de las mismas. Durante la colonia y hasta finales del S. XIX, los indios y los negros protagonizaron esa lucha, defendiendo territorios invadidos por los explotadores de tierras y colonizadores, o uniendo la lucha por la libertad con la de la tierra propia y construyendo los quilombos ${ }^{4}$. A finales del siglo XIX e inicios del XX, surgieron movimientos campesinos mesiánicos, que seguían a un líder carismático, como los movimientos de Canutos, con Antonio Conselheiro ${ }^{5}$, del Contestado, con el padre J osé María, y del Cangaço, con Lampiao, y otras luchas de ámbito regional.

En las décadas de 1930 y 1940 hubo conflictos violentos en diversas regiones con ocupación de terrenos abandonados; los ocupantes utilizaron las propias armas para defenderse. Entre 1950 y 1964, el movimiento campe-

3 Véase, M. Morissawa (2001), A História da luta pela terra e o MST, Saõ Paulo, Expressao Popular, 256 pp e ilustracs.; Revista Sem Terra (trimestral); Jornal Sem Terra (mensual); Web MST www.mst.org.br

4 Grupos de resistencia de esclavos negros.

5 Este movimiento dio pie a una importante literatura, entre la que se encuentra recientemente La guerra del fin del mundo de M. VARGAS LLOSA. 
sino se organizó como clase y surgieron las Ligas Campesinas, la Unión de los Labradores y Trabajadores Agrícolas del Brasil (ULTAB) y el Movimiento de los Agricultores Sin Tierra (MASTER). Estos movimientos fueron aplastados por la dictadura militar (1964) y sus líderes fueron asesinados, apresados 0 se exiliaron. Los latifundistas derrotaron, en aquel momento, a los defensores de la reforma agraria. Pero entre 1979 y 1980, en medio de la lucha por la redemocratización, surge una nueva forma de presión de los campesinos: las ocupaciones organizadas por centenas de familias. El MST nació, en ese contexto, por la conjunción de distintos factores socioeconómicos existentes en el periodo 1975-85: el proceso de desarrollo capitalista en la agricultura, que provocó la concentración de la tierra y el consecuente aumento de campesinos sin tierra; el proceso de transición conservadora que aisló a la dictadura militar y animó a los campesinos a organizarse; la labor pastoral de la Iglesia católica, en particular de la Comisión Pastoral de la Tierra, que impulsó a los campesinos a organizarse; y las luchas aisladas por la tierra que empezaran a sucederse en distintos Estados. Como resultado de la articulación de esas luchas concretas y gracias a la obstinación de los luchadores por conquistar la tierra, se ha fundado el movimiento en el ámbito nacional en un histórico congreso celebrado en enero de 1985, en la ciudad de Curitiba (Paraná), con la participación de 1.500 representantes campesinos de todo el país.

\section{Organización, configuración y relaciones del MST}

El Movimiento decidió organizarse por comisiones de campesinos, como la Comisión de Base, en las comunidades rurales, para organizar la lucha por la tierra, las Comisiones de municipios, las Comisiones Estatales ${ }^{6}$ y la Comisión Coordinadora Nacional. Las comisiones son también la forma de organización en el interior de los asentamientos y campamentos. En el Movimiento no hay funciones de presidente, secretario y tesorero, y su órgano máximo es el Congreso Nacional del MST, que se celebra cada cinco años. Anualmente se celebran encuentros nacionales y estatales; asimismo hay comisiones ejecutivas nacionales y por cada Estado. En la administración, hay una secretaría nacional que orienta las deliberaciones en el ámbito

6 Brasil es un Estado federal con 23 Estados. El término nacional en esta nota hace siempre referencia al ámbito federal brasileño, mientras que estatal es usado para cada uno de los Estados. 
nacional por medio de las secretarías de los Estados. El MST está organizado actualmente en todos los Estados de Brasil.

La organización pretende organizar formas de lucha y reivindicaciones concretas, con las siguientes acciones: 1) organización de los campesinos, que luchan por la tierra en la base y construcción de un amplio movimiento social de masas, que recupere la lucha por los derechos humanos de las mayorías populares; 2) concienciación de la sociedad y, especialmente, de los sectores urbanos, sobre la reforma agraria como una lucha de todos, que implica transformaciones económicas, políticas y sociales que beneficiarán a toda la sociedad y, por eso, no interesa tan sólo a los sin tierra; 3) desarrollo de todas las formas de presión popular para garantizar que el Gobierno ponga en marcha el proceso de reforma agraria: manifestaciones, marchas, audiencias públicas, caminatas, huelgas de hambre, vigilias, acampadas y ocupaciones de latifundios para que sean expropiados.

Precisamente, para la ocupación legal de latifundios y que estos sean expropiados existe una base constitucional que es la que sirve de fundamento jurídico al MST. La Constitución de Brasil, aprobada por el Congreso Nacional en 1988, plantea el principio de que el Gobierno debe realizar una reforma agraria, aunque sin afectar a las propiedades que sean productivas. Hace falta, como es obvio, que leyes complementarias definan lo que es propiedad productiva. El MST, por su parte, presentó en 1987, conjuntamente con las demás entidades del movimiento sindical -CONTAG (Confederación Nacional del los Trabajadores en la Agricultura) y CUT (Central Única de los Trabajadores)- un proyecto de reforma agraria firmado por un millón doscientos mil electores, quefue rechazado por el Congreso Nacional, contra el que también se manifestó el gobierno. Por entender la reforma agraria como una necesidad social en Brasil, el MST decidió seguir luchando, no sólo con una batalla legal, sino combinando ésta con la lucha directa de los trabajadores. Podemos hablar, pues, de un movimiento que combina la desobediencia civil y la "legalidad" de las ocupaciones. Por un lado, la ocupación es, en sí, un acto de desobediencia civil frente a las leyes vigentes. Los sin tierra, sin embargo, entienden que la ley que protege la propiedad particular de un latifundio que concentra dicha propiedad de la tierra, que produce poco, y que impide al acceso de millones de personas a una vida digna, es una ley injusta.

Por ello, el MST piensa que ningún ser humano está obligado a obedecer leyes injustas. La desobediencia civil, deso bedecer pública y deliberadamen- 
te una ley considerada injusta, es, desde hace muchos siglos, un instrumento de lucha de los movimientos populares contra leyes injustas y a favor de la vida. Por otra parte, hay hoy, en Brasil, muchos juristas famosos que consideran que el latifundio que no cumple una función social es no sólo injusto, es contrario a la ley; y defienden que las ocupaciones no sólo son justas, sino legales, pues son una forma de poner en práctica el mandato constitucional de realizar la reforma agraria y hacer que las tierras cumplan con su función social. Según estos juristas, cabría a su juicio, antes de una ocupación, ordenar una valoración técnica del área ocupada y, si se confirmase que es un latifundio improductivo o no suficientemente productivo, declarar la expropiación del mismo; el Gobierno debería indemnizar al propietario con títulos del gobierno, como los títulos de deuda agraria, pagaderos en veinte años; y así los trabajadores pasarán a hacer producir ese latifundio, dando una función social a aquella tierra. No ha sido este el procedimiento aplicado por los jueces, que se han limitado, por falta de coraje, a aplicar la Constitución, limitándose a la cómoda situación de aplicar el Código Civil, por lo que ordenan el desalojo de las familias. Lo que se ha logrado últimamente es que los plazos dados por los jueces para la devolución de las posesiones (desalojo) sean más largos, permitiendo, así, más tiempo de negociación con el Gobierno en busca de soluciones, por los menos provisionales, para la situación de las familias ocupantes.

Las relaciones del MST con otros movimientos sociales forman parte de la propia estrategia del mismo. EI MST apoya la "doble militancia" y el aprovechamiento de los cauces legales existentes e impulsa a to dos los campesinos para que se afilien y participen en el Sindicato de Trabajadores Rurales, que es la organización sindical existente en cada municipio. Como central sindical, el MST searticula con la Central Única de los Trabajadores (CUT) y apoya, participa y estimula diversos centros regionales de investigación y asistencia técnica alternativa, como CETEP (RS), ASSESSOR (PR) y el Proyecto Tecnologías Alternativas de Base. En los aspectos relacionados con la tarea pastoral, el MST mantiene relaciones con la Comisión Pastoral de la Tierra y las delegaciones de pastoral rural de las diócesis. En el ámbito internacional, el MST mantiene relaciones con todas las organizaciones campesinas de Latinoamérica. Aunque no está afiliado a organismos sindicales internacionales, tiene el apoyo y solidaridad de diferentes organizaciones de trabajadores y no gubernamentales de Europa y Canadá. 


\section{Objetivos del MST: la lucha por la reforma agraria en Brasil}

EI MST apunta hacia tres grandes objetivos: la tierra, la reforma agraria y una sociedad más justa, y para ello lucha por una expropiación de las grandes áreas en manos de multinacionales, y por que se acabe con los latifundios improductivos, consiguiendo que sea definida la superficie área máxima en hectáreas que puede tener una propiedad rural. El MST está en contra de los proyectos de colonización, que han resultado un fracaso en los últimos treinta años y quiere una política agrícola, en beneficio del pequeño productor. EI MST defiende la autonomía para las áreas indígenas, por lo que es contrario a la revisión de la propiedad de la tierra de esos pueblos, amenazados por los latifundistas. Por otra parte, apunta hacia la democratización de la gestión del agua en las áreas de regadío en el Nordeste, asegurando la permanencia de los agricultores en la propia región. Entre otras propuestas, el MST lucha a favor de un castigo justo a los asesinos de trabajadores rurales y defiende el cobro del Impuesto Territorial Rural (ITR), destinando los resultados de su recaudación a la reforma agraria.

\section{Las conquistas del MST}

EI MST está organizado como entidad nacional desde 1984. Desde entonces ha conseguido muchos logros e importantes conquistas. Fueron más de 3.900 los latifundios ocupados, que después se transformaron en proyectos de asentamiento para más de cuatrocientas cincuenta mil familias de trabajadores rurales, sumando más de veintidós millones de hectáreas recuperadas y transformadas. El desarrollo de la producción en esos asentamientos está muy diferenciado, en razón del potencial de las tierras expropiadas, de las oportunidades del mercado, del acceso al crédito gubernamental (PRoceRA) y de las políticas agrarias oficiales. En todo caso, las investigaciones y los informes oficiales coinciden en señalar que las familias ya no pasan hambre en los asentamientos, que todos mejoraron su nivel de vida en comparación con la situación anterior al asentamiento, y que todas las áreas ocupadas producen, significativamente, mucho más que cuando estaban en manos de los latifundistas. En términos de política rural el MST conquistó del Gobierno la implantación de una línea especial de crédito rural para los asentamientos, que se llama Procera. Éste destina anualmente en torno a los 100 millones de dólares para las familias asentadas, con intereses subsidiad os y condiciones de devolución más adecuadas y favorables para los beneficiarios. EI MST desarrolla un sector específico para acompañar y organizar la producción y 
la comercialización, que se llama Sector Cooperativista de los Asentados (ACA). El Movimiento pone énfasis en las formas de organización colectiva y cooperativa. Gracias a éste ya se han organizado más de cuatrocientos formas diferentes de asociaciones. Hay ochenta y tres cooperativas de producción colectiva, ocho cooperativas centrales de ámbito estatal ${ }^{7}$ y una confederación nacional de las cooperativas de la reforma agraria. En muchos asentamientos se instalaron pequeñas industrias agrarias. Hay casos ejemplares que destacan por la producción, que supera a las empresas capitalistas instaladas desde hace años.

También se ha conformado un sector de educación, con la intención de democratizar la enseñanza, tanto para los niños como para los adultos de los asentamientos, y a favor de una escuela pública de calidad. Este sector busca organizar las escuelas de primera etapa en los asentamientos y también dar capacitación específica al profesorado, con métodos adecuados a su tarea pedagógica. El sector organiza además cursos especiales de segundo nivel, en los que pueden estudiar los asentados y así prepararse como profesores (cursos de magisterio) y como técnicos en administración cooperativa. Por otro lado, se anima a los alumnos para que sigan estudiando, y ya hay más de ochenta de ellos matriculados en universidades. Los niveles iniciales de instrucción y las energías dedicadas a la lucha explican este número aparentemente bajo.

Ya en 1992 la FAO (organismo de las Naciones Unidas para la agricultura y la alimentación) hizo una investigación en todos los asentamientos del Brasil para evaluar su situación real y pudo constatar que, entre otros indicadores socio-económicos, la renta media de una familia asentada equivale a 3,7 salarios mínimos, muy por encima de la renta media del trabajador rural normal; el paro de la mano de obra es tan sólo del 14\%, más baja que la tasa de paro nacional, y el capital de las familias se revalorizó en un $250 \%$ después de que fueran asentados. Este estudio señaló también que la mortalidad infantil promedio en los asentamientos disminuyó a 15 por mil, mientras que para el conjunto del país se aproxima al 100 por mil (aunque hay que observar que en las regiones sur y sudeste prácticamente ha sido eliminada). A pesar de todas las dificultades derivadas de la falta de apoyo gubernamental, el nivel de abandono promedio de las familias de los asentamientos a escala nacional es del $22 \%$, lo que es considerado por la FAO como satisfactorio, comparando estos datos con los de otros procesos de asenta-

\footnotetext{
7 De cada Estado federado.
} 
miento en todo el mundo. Sin embargo en Brasil todavía puede ser considerado como elevado, ya que hubo muchas deserciones de los proyectos de colonización en las regiones del norte brasileño, donde persisten las peores condiciones de vida, a causa de la presencia de la malaria y la falta deatención médica. En la región nordeste el nivel de abandono baja al 5\%, y en la región sur y sudeste es de sólo el $4 \%$.

\section{Perspectivas para el MST}

El Movimiento tiene más de 15 años, en los que viene luchando intensamente contra el latifundio. Entre las formas principales de lucha están las ocupaciones de tierras, la realización de marchas sobre las capitales estatales, las asambleas masivas, las caminatas, las manifestaciones, las tomas de edificios gubernativos, etc. EI MST ha sido duramente combatido por el Gobierno, por los latifundistas y por las elites; la sociedad y la opinión pública lo veía como si se tratase de verdaderos Quijotes, luchando contra los molinos de viento... Esta lucha incesante ha conseguido avances importantes, ya citados: latifundios conquistados a la burguesía agraria terrateniente, asentamiento de miles de familias; el avance en la construcción de una nueva propuesta de reforma agraria, vinculada a los intereses de toda la población y no exclusiva y aisladamente de los sin tierra, una reforma agraria que implique la quiebra del problema agrario por sus raíces, una propuesta de reforma agraria que represente más igualdad social y justicia en el campo, y conlleve un desarrollo económico bajo control de los trabajadores.

Sin embargo, el mayor avance del Movimiento ha sido el proceso de concienciación de toda la sociedad. En el Congreso de Brasil, en 1995, ya se podía levantar la bandera de "La reforma agraria es una lucha de todos". Concienciar a los trabajadores de la ciudad, y a la población en general, es parte de la estrategia del MST. De esta forma se presenta a la población más pobre de la ciudad la reforma agraria como un medio fundamental para resolver gran parte de los problemas que se afrontan en las periferias urbanas, como el hambre, el desempleo, la violencia, la marginación, la falta de educación, el transporte y la vivienda. Poco a poco los trabajadores urbanos han comprendido este carácter de la lucha y este enfoque, y hoy podemos avanzar aún más, de manera que vean que la reforma agraria solamente será posible, no sólo por voluntad de un Gobierno presionado, sino en el marco de la lucha contra el neoliberalismo y el imperialismo ideológico y comercial, contra la dependencia del capital financiero, contra 
la dominación del capital. El desarrollo humano sólo es posible con un nuevo modelo nacional, que atienda a todos los brasileños, y popular, que atienda las necesidades básicas de todo el pueblo y no solamente de una minoría, como es la política neoliberal.

EI MST está convencido de que en Brasil, en Latinoamérica y, en general, en los países del Tercer Mundo solamente es posible alcanzar la reforma agraria con profundos cambios económicos y sociales, hechos por todo el pueblo organizado. Hay muchos retos por delante. Las ideas socialistas y los proyectos de transformación y emancipación social pasan por una crisis. Hace falta, todavía, recuperar más la confianza en nuestros pueblos. Hay que comprender que solamente organizando a las masas y haciendo grandes movilizaciones populares se lograrán cambios. Para esto hay que volver a hacer un trabajo de formación político-ideológica y recuperar formas creativas de comunicación con las masas. EI MST parte de que el futuro pertenece a la clase trabajadora y lucha por recuperar la mística de que son posibles los cambios sociales y, asimismo, es posible recuperar el ánimo para los cambios necesarios, rumbo a una verdadera democracia que sea camino para una sociedad más justa. 